\title{
KISMAMARTA : INTERPRETASI SEJARAH DAN KONFLIK DI KAMPUNG SAYIDAN YOGYAKARTA
}

\author{
Antonius Ragipta Utomo \\ Penciptaan musik, Pascasarjana \\ Institut Seni Indonesia, Surakarta \\ email: ragiptautamakarya@gmail.com
}

\begin{abstract}
ABSTRAK
Keberadaan tanah di Kampung Sayidan Daerah Istimewa Yogyakarta sampai sekarang masih berstatus quo, hal itu membuat masyarakat tidak tenang dan gelisah. Masyarakat sebenarnya hanya ingin tahu tentang kepastian hak milik tanah di kampung tersebut yang selama ini sudah mereka tempati berpuluh-puluh tahun. Belum lama ini, terjadi hal yang semakin meresahkan masyarakat. Adanya oknum dari luar masyarakat yang membeli tanah di Sayidan, namun setelah dibeli rumah tersebut dibongkar dan tidak dipakai. Penyusunan karya ini mengangkat objek tentang Kampung Sayidan yang berjudul Kismamarta. Karya tersebut menginterpretasikan sejarah, konflik, dan sosial masyarakat di Kampung Sayidan. Penggarapan karya musik ini disusun dengan format musik ansambel. Karya komposisi ini disusun menggunakan perpaduan antara alat musik dengan alat-alat musik nonkonvensional sebagai sumber bunyi. Karya dalam Kismamarta mempunyai bentuk eksplorasi. Bentuk eksplorasi karya ini dituangkan ke dalam empat bagian karya. Keempat bagian karya tersebut menginterpretasikan tentang sejarah Sayidan, sosial masyarakat, konflik tanah, dan perenungan.
\end{abstract}

Kata Kunci : kismamarta, interpretasi, kampung sayidan, ansambel, eksplorasi.

\begin{abstract}
The land existence in Sayidan Kampong, the Special Region of Yogyakarta, has a quo status up to now. That status make the people uneasy and fidgety. Actually, the people only want to know about the certainty of landowners in the kampong which has been dwelled for decades. Recently, there was something happened which make the people become more restless. There was a person outside Sayidan people who bought land in Sayidan, but after that, the house was demolished, and it is now useless. The composer of this work rises an object about Sayidan Kampong entitled Kismamarta. The work interprets a history, conflict, and social community in Sayidan Kampong. The cultivation of this music work was arranged with ensemble music format. This composition work was arranged using a fusion of music instruments and non-conventional music instruments as the sound sources. Work in Kismamarta has a line of exploration. The four parts of the work interprets Sayidan history, social community, land conflict, and reflection.
\end{abstract}

Keyword: kismamarta, interpretation, sayidan kampong, ensemble, exploration. 


\section{A. Pendahuluan}

Karya yang digarap pengkarya menyangkut tentang kepemilikan tanah dan sertifikat tanah. "Kismamarta" adalah tema yang diangkat pengkarya dalam karya. Kisma berarti tanah dan Marta berarti penghidupan. "Kismamarta" adalah gabungan dua kata yang bersumber dari kata Tirtamarta yang berarti air penghidupan. "Kismamarta" adalah intisari sebuah fenomena di Kampung Sayidan, di sana masyarakat hidup, tinggal dan beradaptasi. Kampung itu adalah tempat berkumpulnya keluarga, yang sampai sekarang semua warganya tidak mempunyai sertifikat. Konflik di Kampung Sayidan adalah polemik panjang yang membuat masyarakat gelisah dan bingung, karena status mereka tidak jelas di tanah yang sudah mereka huni puluhan tahun.

Sayidan adalah perkampungan padat penduduk yang wilayahnya berada tepat di pusat kota. Berjarak sekitar 200 meter dari sisi timur Keraton Yogyakarta dan berbatasan langsung pada sebelah barat bantaran Sungai Code. Sekarang tidak kurang dari 500 kepala keluarga mendiami kampung ini. Nama Sayidan berasal dari kata Sayyidina yang berarti tuan-tuan Arab. Dahulu pada masa penjajahan Belanda tanah di kampung ini adalah tempat orang Arab bermukim dan bermata pencaharian sebagai seorang pedagang.
Setelah orang Arab berpindah dan menyebar di berbagai tempat, barulah orang Jawa menamai kampung ini dengan nama Sayidan. "Akhiran-an dalam bahasa Jawa dapat menjadi pemarkah yang bermakna tempat kediaman. Sebagai contohnya adalah Kampung Jageran yang bermakna tempat kediaman Prajurit Jager” (Ardheana, 2018 : 26).

Pada tahun 1994 terjadi kasus konflik tanah di Kampung Sayidan. Peristiwa tersebut terjadi ketika adanya berita yang ditulis di surat kabar Kedaulatan Rakyat 17 Februari 1994 dan ditulis ulang pada 10 Desember 1994 yang isinya adalah surat pemberitahuan kepada masyarakat agar mengosongkan rumah karena akan dihuni oleh yang punya hak milik tanah Sayidan bernama Yap Tjay Ham. Berita di atas membuat semua warga masyarakat Sayidan kaget, dikarenakan selama ini warga merasa adem, ayem, tentrem, dan tidak ada konflik menyangkut masalah tanah.

Sekarang sudah 26 tahun kasus tanah di Kampung Sayidan belum selesai. Sejak dari tahun 1994 sampai tahun 2020 dan belum pernah ada penyelesaian yang pasti. Bahkan sekitar tahun 2013 sudah ada warga yang telah menjual rumahnya kepada pengusaha, namun anehnya adalah setelah dibeli tanah bangunan dirobohkan dan lahan dibiarkan kosong. Hal tersebut sebenarnya sudah melanggar ketentuan dari BPN pasalnya status tanah 
masih quo dan telah dilindungi negara dari masa pemerintahan Presiden Soeharto, dan ketika Ir. Soni Harsono masih menjabat menjadi ketua BPN. Keresahan warga Sayidan semakin memuncak pada Desember 2013. Berita yang ditulis pada media web republika.co.id menyatakan bahwa, sekitar 90 kepala keluarga dari Kampung Sayidan, Kelurahan Prawirodirjan, Kecamatan Gondomanan Daerah Istimewa Yogyakarta mendatangi kantor DPRD setempat (republika.co.id, 24 Desember 2019). Warga menuntut kejelasan akan kepastian tanah di Sayidan yang selama ini telah mereka huni dan tempati, namun tidak pernah ada titik temunya atau mendapat penyelesaiannya.

Ketertarikan pengkarya akan permasalahan di Kampung Sayidan dikarenakan pengkarya sejak kecil sudah tinggal di kampung tersebut sejak pengkarya kelas 4 Sekolah Dasar (SD). Pertalian emosi dan kenangan semasa kecil dengan temanteman kampung dan warga sangat membekas di dalam diri pengkarya. Rumah di Sayidan sebenarnya adalah rumah tinggal kakek dan nenek pengkarya, satu keluarga diminta untuk tinggal di rumah tersebut karena kakek dan nenek sudah tua. Dalam perjalanan waktu ketika pengkarya remaja dan menginjak Sekolah Menengah Pertama (SMP) barulah pengkarya mengetahui bahwa tanah di Sayidan tidak mempunyai sertifikat.
Masyarakat di Sayidan sering gusar dan gelisah akan hal tesebut. Warga hanya bisa mendugaduga dan bertanya kenapa mereka tidak bisa mendapat hak mereka atas tanah dan rumah yang sudah mereka tempati berpuluh-puluh tahun. Kegelisahan dan rasa prihatin menjadi motivasi pengkarya dalam memilih persoalan tanah Kampung Sayidan menjadi objek dalam penciptaan karya. Karya ini adalah media yang dipakai pengkarya untuk mengungkapkan kegelisahan dan keprihatinan dengan kampungnya sendiri.

\section{Intepretasi : Hermeneutik dan Semiotika}

Intepretasi tidak bisa lepas dari konsep hermeneutik, Sumaryono (1999: 2324), Wachid dalam jurnal "hermeneutika sebagai sistem interpretasi paul ricoeur dalam memahami teks -teks seni” terbit dalam jurnal Imaji, Vol.4, No.2, Agustus 2006 : 198 - 209 memberikan uraian mengenai konsep hermeneutik yang berasal dari bahasa Yunani hermeneuein yang berarti "menafsirkan", dan kata bendanya hermeneia yang berarti "penafsiran" atau "interpretasi”, dan kata hermeneutes yang berarti interpreter (penafsir). Istilah Yunani berkenaan dengan kata "hermenuetik" ini dihubungkan dengan nama dewa Hermes, yaitu seorang dewa yang mempunyai tugas menyampaikan pesan pesan Jupiter kepada umat manusia, 
menerjemahkan pesan -pesan dari dewa-dewa ke dalam bahasa yang dapat dimengerti oleh manusia. Tugas ini menjadi penting sebab jika terjadi kesalah -pahaman dalam menginterpretasikan pesan dewa akibatnya akan fatal bagi umat manusia.

Palmer (2003:15-36) bahwa mediasi dan proses membawa pesan "agar dipahami" yang diasosiasikan dengan Dewa Hermes itu terkandung dalam tiga bentuk makna dasar. Pertama, sebagai "to express" (mengungkapkan), “to assert” (menegaskan), atau "to say" (menyatakan), hal ini terkait dengan fungsi "pemberitahuan". Kedua, sebagai “to explain" (menjelaskan), interpretasi sebagai penjelasan menekankan aspek pemahaman diskursif. Interpretasi lebih menitikberatkan pada penjelasan daripada dimensi interpretasi ekspresif. Hal yang paling esensial dari kata-kata bukanlah mengatakan sesuatu, menjelaskan sesuatu, merasionalisasikannya, membuatnya jelas. Seseorang dapat mengekspresikan situasi tanpa menjelaskannya, dan mengekspresikannya merupakan interpretasi, serta menjelaskannya juga merupakan bentuk interpretasi. Ketiga, sebagai "to translate". Pada dimensi ini "to interpret" (menafsirkan) bermakna "to translate" (menerjemahkan) yang merupakan bentuk khusus dari proses interpretatif dasar "membawa sesuatu untuk dipahami”.
Wilayah intepretasi bukan hanya sekedar pada aspek bahasa, tetapi bisa berdasarkan faktor sosial budaya yang terdapat dalam aktifitas masyarakat, sehingga salah satu kajian yang menarik adalah semiotika atau ilmu terntang intepretasi tanda yang diuraikan oleh Sausure tentang konsep langanage dan parole, lebih kepada bahasa sedangkan konsep triangle oleh Pierce (1931) juga memberikan sebuah konsep semiotik terdiri dari tiga elemen yakni tanda (sign), acuan tanda (object), dan penggunaan tanda (Interpretant) atau disebut teori segitiga makna atau triangle meaning. Tanda adalah sesuatu yang berbentuk fisik yang dapat ditangkap oleh panca indera manusia dan merupakan sesuatu yang merujuk (merepresentasikan) hal lain di luar tanda itu sendiri. Tanda menurut Peirce (dalam Nugraha, Sumerjana: 2015) terdiri dari Simbol (tanda yang muncul dari kesepakatan), Ikon (tanda yang muncul dari perwakilan fisik) dan Indeks (tanda yang muncul dari hubungan sebab-akibat).Sedangkan acuan tanda ini disebut objek.Objek atau acuan tanda adalah konteks sosial yang menjadi referensi dari tanda atau sesuatu yang dirujuk tanda.Interpretant atau pengguna tanda adalah konsep pemikiran dari orang yang menggunakan tanda dan menurunkannya ke suatu makna tertentu atau makna yang ada 
dalam benak seseorang tentang objek yang dirujuk sebuah tanda

Konsep musik dari pengkarya berjudul "Kismamarta" yang berarti tanah penghidupan. Karya ini adalah sebuah komposisi musik yang menginterpretasikan tentang sebuah gambaran tentang sejarah dan konflik di tanah Kampung Sayidan. Konsep karya ini tumbuh dari kecintaan pengkarya akan keberadaaan tanah yang memberi pijakan kepada keberlangsungan kehidupan masyarakat di kampung tersebut. Berangkat dari rasa memiliki, cinta, dan kepedulian terhadap tanah berserta fenomena yang terjadi di kampung tersebut pengkarya menuangkan gagasan tersebut ke dalam empat bagian karya yang di mana empat bagian karya tersebut menginterpretasikan awal mula Kampung Sayidan, situasi masyarakat, konflik masyarakat saat ini, dan perenungan masyarakat akan keberadaan mereka di Kampung Sayidan

\section{B. Metode Penelitian Penciptaan}

Dalam penyusunan karya musik "Kismamarta" ini, pengkarya melakukan sebuah metode yang secara garis besar memiliki tiga tahap yaitu, menyusun gagasan isi, menyusun ide garapan, dan menentukan garapan. Adapun penjelasan dari tahapan tersebut dapat diuraikan sebagai berikut.
Menyusun gagasan isi. Dalam gagasan isi di sini seperti yang telah dipaparkan dalam konsep karya penyusunan gagasan isi dilakukan untuk mendapatkan ide garapan pada setiap karya. Bagian pertama berjudul "Rangkul", rangkul sering diartikan sebagai sebuah ungkapan kedekatan yang dilakukan dengan melingkarkan salah satu lengan pada pundak. Namun kata ungkapan pada rangkul tersebut tidak diartikan secara harafiah, ungkapan tersebut diartika mengenai kedekan orang Jawa dengan kaum pendatang atau orang Arab. Karya ini menginterpretasikan fenomena tentang awal sejarah Sayidan, di mana dahulu banyak tuan Arab bermukim ditempat ini. Karya ini juga menerjemahkan suasana sisi religius masyarakat pada waktu tersebut dan bagaimana masyarakat Jawa menerima budaya pendatang yang masuk ke dalam lingkungannya. Bagian kedua berjudul "Ledok Labirin", bersumber dari dua padanan kata ledok dan labirin. Ledok berarti tanah dataran rendah dan labirin yang dikutip dari Kamus Besar Bahasa Indonesia yang berarti tempat yang penuh dengan jalan dan lorong yang berliku-liku dan simpang siur. Bagian kedua menginterpretasikan tentang lika-liku dan seluk beluk kehidupan masyarakatnya yang heterogen. Karya "Ledok Labirin" menginterpretasi segala bentuk sosial warga, interaksi antarwarga dan segala sudut pandang masyarakat Sayidan. Bagian ketiga berjudul 
"Tidha-tidha". Tidha-tidha yang berarti samar menerjemahkan suasana konflik tanah Sayidan yang sampai sekarang masih melanda masyarakat. Bagian ini menginterpretasikan kepanikan, kebingungan, dan segala kecemasan sama seperti yang dialami warga Sayidan saat ini. Bagian keempat berjudul "Wening" yang berarti hening. Hening di sini bukanlah diam namun sebuah kesadaran dalam kejernihan hati dan pikiran. Bagian keempat ini mengungkapkan sebuah renungan, refleksi, dan kontemplasi dari sejarah awal Kampung Sayidan sampai dengan konflik tanah. Renungan ini yang diimplementasikan ke dalam musik dan dikembalikan kepada masyarakat sebagai sebuah pertanyaan bahwa masih berhargakah tanah bagi kita untuk kehidupan dan keberlangsungan anak cucu dan bukan semata kekuasaan serta uang.

Menyusun ide garapan. Dalam penyusunan ide garapan ini agar pengkarya dapat menginterpretasikan karya dibutuhkan alat musik sebagai sebuah sarana. Instrumen atau sarana yang digunakan di dalam menginterpretasikan gagasan karya tersebut dipilih dari proses di mana pengkarya mulai mendapat gagasan isi tentang situasi di Sayidan. Pada karya pertama pengkarya menggunakan alat musik gitar, syntheziser tablet, krincing, rebana, kendang ciblon, dan untuk eksperimen suara pengkarya menggunakan ember, sarung dan jeriken air. Karya kedua pengkarya bermain solo dengan instrumen gitar akustik elektrik dan menggunakan sandal teklek sebagai sumber bunyi. Dalam bagian ini juga menggunakan video LCD proyektor yang dimainkan duet oleh pengkarya. Karya ketiga pengkarya menggunakan gitar synthesizer, drum, synthe tablet, elektrik efek, dan perkusi dari alat-alat nonkonvensional seperti panci, ember, dan seng genteng. Sebagai bentuk ekplorasi musik dalam karya, pengkarya menggunakan papan catur yang dibuat sendiri dan diimplementasikan sebagai sumber bunyi dan ekplorasi suara. Dalam karya keempat, pengkarya menggunakan alat ciptaan sendiri yang dinamakan dangtar. Alat ini berasal dari dandang yang diberi dryer dan dipasang senar gitar. Pengkarya juga menggunakan alat musik snare drum, siter, dan synth tablet. Sebagai bentuk eksplorasi bunyi pengkarya menggunakan gelas, panci, korek api, krupuk, dan berbagai macam sikat pembersih rumah.

Menentukan garapan. Garapan secara keseluruhan digarap ataupun disusun dengan eksplorasi alat musik, perpaduan dengan alat musik yang diciptakan, dan beberapa alat pendukung karya yang digunakan sebagai bentuk eksperimen di dalam karya. Secara penggarapan setiap bagian karya saling terkait. Alat dipilih sebagai daya ungkap suasana. Pada bagian pertama tiga penyaji dipilih khusus 
untuk memainkan ember, kain sarung, dan jeriken air. Penggarapan dari ember, sarung dan jeriken serta gerakan menuangkan air dalam ember tidak diam ditempat, hal ini dikarenakan pertimbangan efek suara dan cara memainkannya. Pada karya pertama ini pengkarya memainkan gitar sebagai bentuk landasan melodi dan harmoninya. Dalam karya ini juga gitar dimainkan jalan sesekali berputar memutari ketiga pemain ember, sarung dan jeriken air. Pengkarya rebana memulai bermain dari sudut pengkarya berjalan dibelakang ketiga pemain alat musik nonkonvensional dan berhenti di sebelah ujung kiri stage. Pengkarya memutuskan untuk menempatkan pemain synthe bermain musik ditempat. Pada bagian kedua pengkarya sebagai pemain gitar naik ke tingkat dan mengawali musik dari atas sampai ke bawah stage. Pertimbangan ini diambil karena pengkarya ingin mengeksplorasi suara sandal teklek dan bunyi dari gitar yang bergerak. Pada bagian ketiga latar berpindah dari solo gitar ke pemain catur yang sudah siap di atas meja. Karya ketiga ini adalah elaborasi antara pemain catur dan pemusik yang bermain melingkari pemain catur. Catur dibuat segitiga dengan pemain tiga orang. Musik dikomposisikan dengan gerakan dari bunyi catur dan suara instrumen musik. Pada bagian ketiga musik dimainkan dengan duduk lesehan di meja diawali dengan ketiga pemain yang duduk lesehan. Musik disitu dengan suara senandung, menuangkan air dan minum teh. Selanjutknya pemain dangtar duduk disambung pemain panci dan syn dan disambung lagi pemain snare drum dan siter duduk satu meja dan berinteraksi musikal memainkan alat musik yang penyaji bawakan dengan sikat pembersih.

\section{Hasil dan Bahasan}

Karya pencipataan musik "Kismamarta" adalah sebuah karya yang mempunyai empat bagian karya yang keempat bagian karya tersebut berkesinambungan dan runtut. Pada bagian pertama berjudul "Rangkul" karya ini mengeksplorasi bunyibunyi dari alat musik nonkonvensional seperti ember, sarung, dan air di jeriken. Alat musik nonkonvensional tersebut dielaborasikan dengan gitar, synth dan rebana. Dalam penggarapan karya pada "Kismamarta" semua pemain bergerak dan tidak diam ditempat, semua bergerak dengan atraktif seperti dalam pertunjukan teater. Gerak tersebut bertujuan untuk menghidupkan pertunjukan musik yang disajikan dan juga bertujuan agar sumber suara tidak hanya ada di satu titik namun juga mengeksplorasi ruang. 


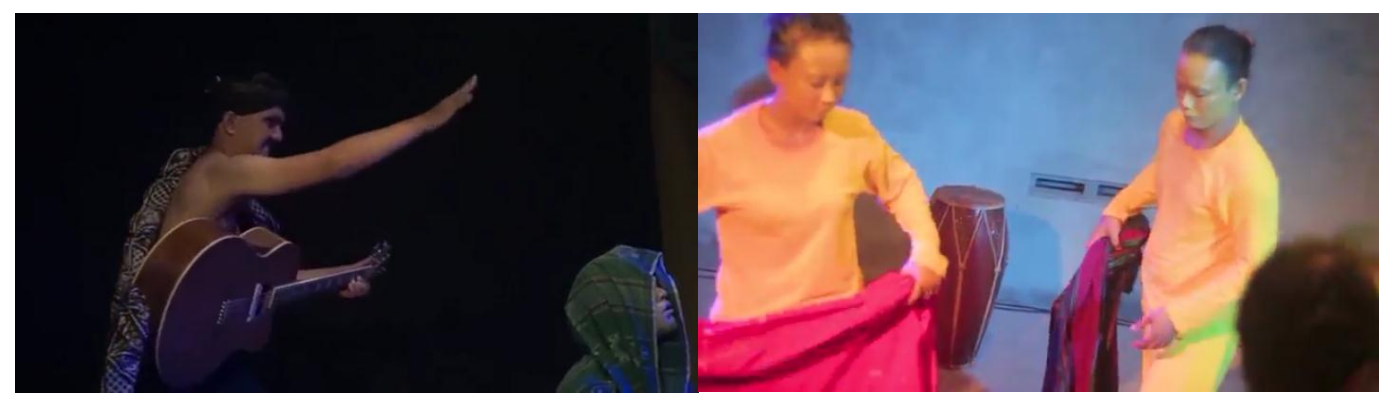

Gambar 1 Ekspresi pengkarya (gitar) dan penyaji

Sumber : Ragipta, 2020

Pengkarya menggunakan notasi balok dan notasi simbol yang perkarya buat untuk membantu memudahkan penyaji dalam membaca notasi.

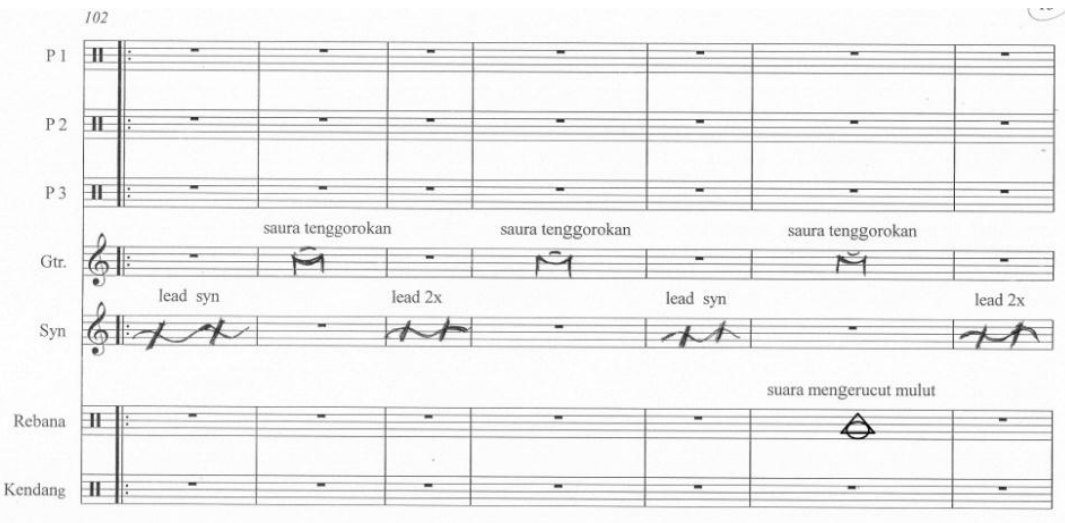

Gambar 2 Cuplikan notasi simbol "Rangkul"

Sumber: Ragipta, 2020

Karya bagian kedua berjudul "Ledok Labirin" karya ini dimainkan solo gitar oleh pengkarya. Kabaharuan kekaryaan di sini terletak pada eksplorasi permainan gitar yang dipadukan dengan bunyi sandal teklek. Bunyi teklek dimainkan dengan perpaduan permainan gitar akustik elektrik. 


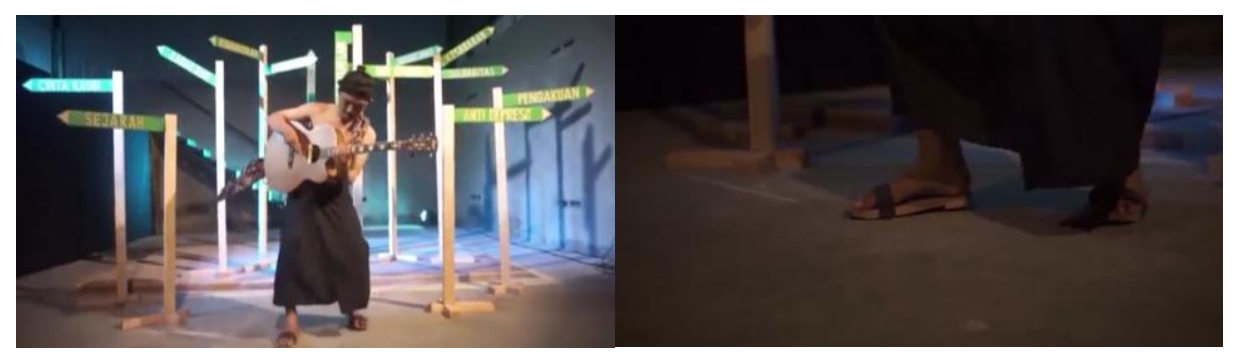

Gambar 3 Permainan gitar menggunakan teklek

Sumber: Ragipta, 2020

Partitur karya "Ledok Labirin" menggunakan penulisan notasi balok karena permainan gitar memainkan tema yang harmonis dan melodis sehingga masih memungkinkan untuk ditulis dalam bentuk notasi balok. Teklek di sini terkadang dimainkan sendiri dan juga dimainkan unison dengan gitar. Penulisan bagian teklek di dalam partitur tidak ditulis notasi balok atau simbol, namun hanya ditulis tulisan sebagai arahan untuk dimainkan

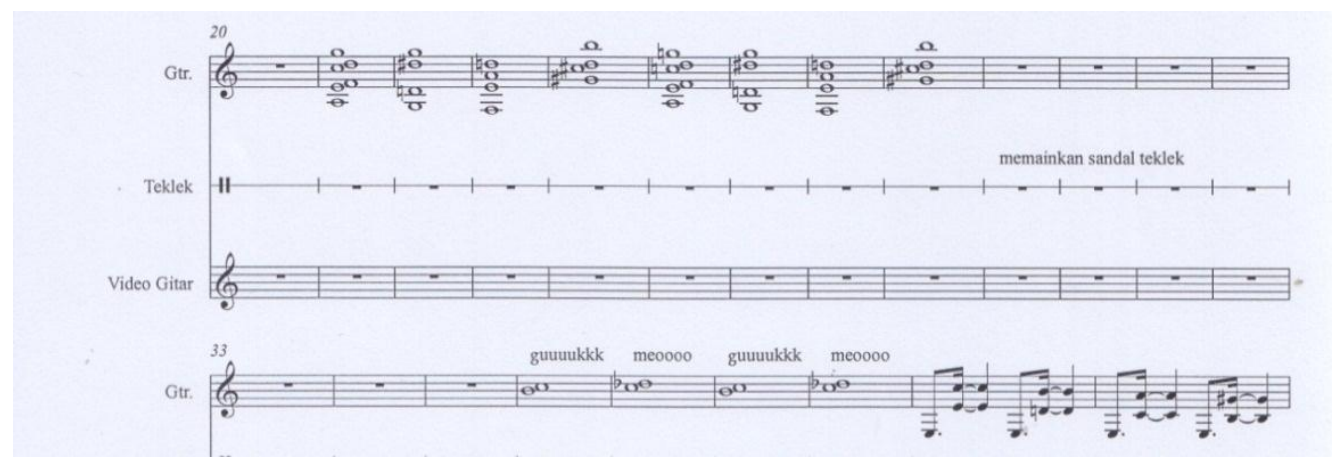

Gambar 4 Partitur notasi balok gitar dan teklek

Sumber : Ragipta, 2020

Karya bagian ketiga berjudul "Tidhatidha" karya ini adalah eksplorasi bunyi dari papan catur yang berbentuk segitiga. Permainan catur tersebut dielaborasikan dengan gitar elektrik synth, drum, elektrik efek, synth tablet, dan instrumen nonkonvensional seng dan panci. Ketiga penyaji memainkan catur ditengah dan dikelilingi penyaji musik. Di dalam karya ini dimainkan seperti dalam teatrikal, namun 
pemain catur sebenarnya tidak bermain catur dalam permainan sesungguhnya namun fokus menghasilkan bunyi ritmis yang direspon penyaji instrumen. Pola gerak dan permain sesuai notasi simbol yang telah ditulis di partitur. Penulisan partitur "Tidhatidha menggunakan notasi simbol.

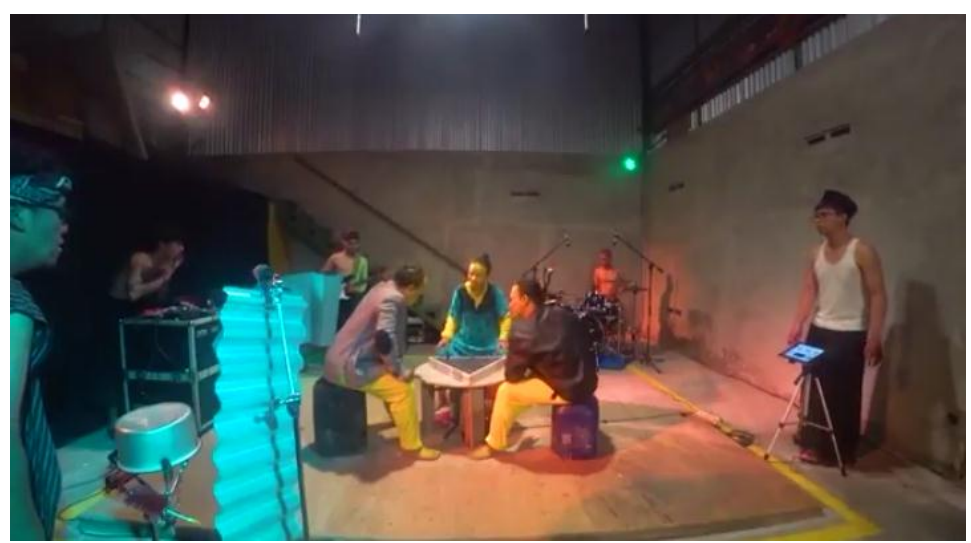

Gambar 5 Permainan catur yang dielaborasikan dengan instrumen musik

Sumber: Ragipta, 2020
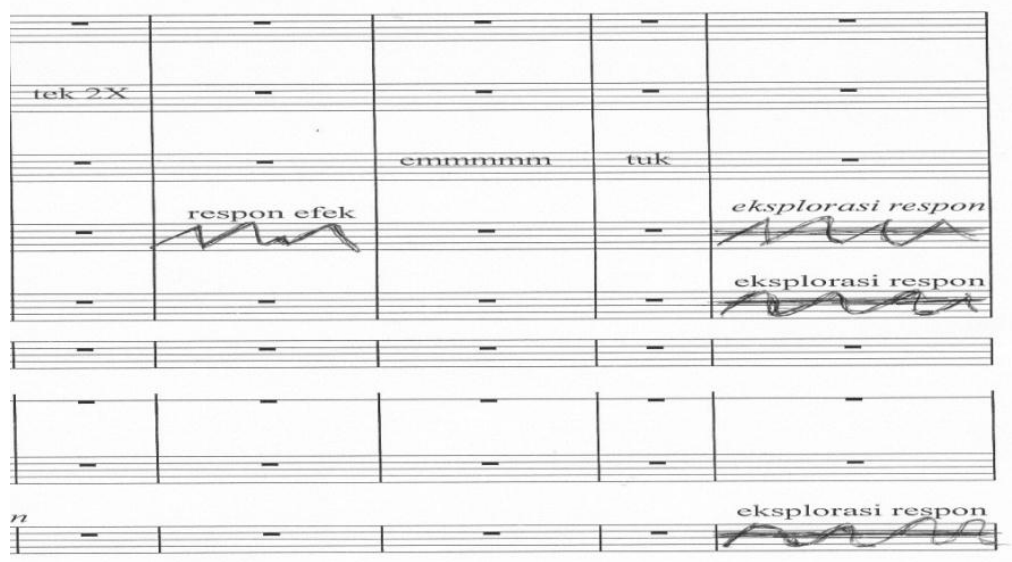

Gambar 6 Notasi Simbol "Tidha-tidha"

Sumber: Ragipta, 2020

Karya bagian keempat berjudul “ Wening" karya ini adalah karya bagian pamungkas dari "Kismamarta". "Wening" dimainkan runtut dari bagian ketiga sampai pada pemain catur meringkasi catur dan papannya dan digantikan dengan 
membunyikan alat-alat yang sudah disediakan dimeja. Pemain musik satu persatu masuk dan membunyikan intrumen yang dibawa. Di karya ini selain mempunyai eksplorasi bunyi juga mempunyai kebaharuan dengan alat yang dibuat pengkarya bernama dangtar. Alat ini terbuat dari dangdang yang dipasang senar gitar.

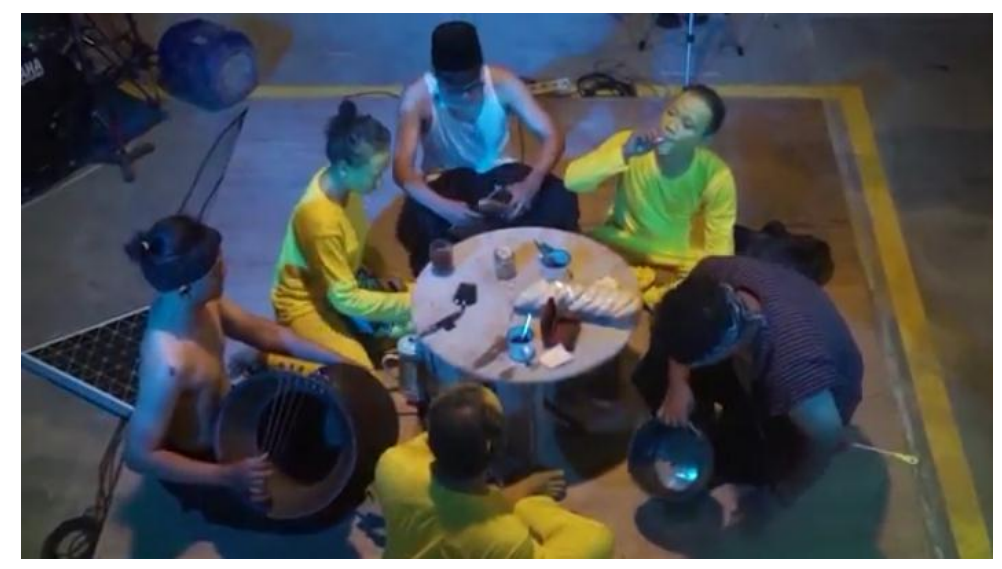

Gambar 7 Pengkarya memainkan dangtar dan penyaji mumbunyikan alat-alat yang ada meja

Sumber : Ragipta, 2020

Partitur "Wening" lebih dominan menggunakan notasi simbol hanya beberapa bagian menggunakan notasi balok pada pola ritmis. Arahan bentuk tulisan juga digunakan untuk mempermudah dalam memainkan karya

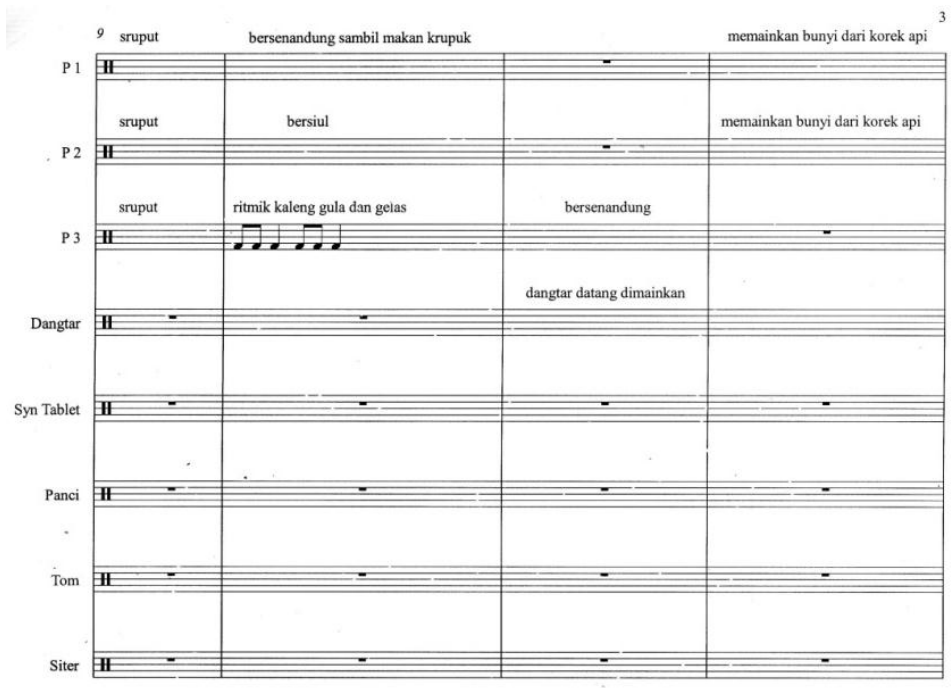




\section{Gambar 8 Notasi balok dan simbol karya Wening}

Sumber: Ragipta, 2020

\section{Simpulan}

Penciptaan karya seni yang berjudul “ Kismamarta" ini diharapkan dapat menjadi bahan rujukan di dalam proses penciptaan karya selanjutnya. Proses penggarapan dan pemakaian alat musik nonkonvensional dapat dijadikan alternatif dalam penggarapan karya. Pengolahan materi-materi ini, dapat dielaborasikan dengan penggunaan alat musik konvensional dan menjadi kebaharuan di dalam pola garap. Harapannya dengan terciptanya karya ini dapat menjadi semangat dan motivasi dalam eksplorasi dan keberanian di dalam menciptakan karya seni, terlebih kepada pengkarya yang mengangkat tentang situasi konflik sosial dan segala bentuk permasalahan yang terjadi di sekitar kita semoga dapat menjadi inspirasi yang mampu menjadi doa dan harapan yang baik.

\section{E. Daftar Pustaka}

Abdul, Wachid B.S. 2006. Hermeneutika sebagai sistem interpretasi paul ricoeur dalam memahami teks -teks seni. Imaji, Vol.4, No.2, Agustus 2006 : $198-209$
Ardheana, Erta. 2018. Pola Pembentukan Dan Dasar Penamaan Nama Kampung Berakhiran -an Di Kota Yogyakarta. Yogyakarta : Sanata Dharma. Ardheana 2018, 26).

Ary, Nugraha Wijayanto and Ketut, Sumerjana (2015) Bunyi Ngumbang Ngisep Gender Wayang Bali Dalam Kajian Semiotika. Mudra, 30 (1). pp. 17. ISSN 0854-3461

Kedaulatan Rakyat.1994. "Sri Sultan : di Yogya tak ada Tanah Negara,"10 Desember 1994. (Kedaulatan Rakyat1994,1).

Palmer, Richard E. 2003. Hermeneutika, Teori Baru Mengenai Interpretasi, terj. Musnur Hery. Yogyakarta: Pustaka Pelajar.

Paul Ricoeur, dalam, John B. Thomson (Ed.). 1982. "Hermeneutics and the Human Sciences, Essays on Language, Action and Interpretation. Cambridge: Cambridge University.

Republika.co.id. (2013, 4 Desember). Status Tanah tak Jelas Puluhan Warga Sayidan Datangi DPRD Yogya. Diakses pada 24 Desember 2019 https://republika.co.id/berita/mxa3 $\underline{\text { sq/status-tanah-tak-jelas-puluhan- }}$ warga-sayidan-datangi-dprd-yogya

Sukerta, Pande Made, 2011, Metode Penyusunan Karya Musik Sebuah Alternatif. Surakarta: ISI Press Solo

Sumaryono, E. 1999. Hermeneutik, Sebuah Metode Filsafat. Yogyakarta: Kanisius 
